\title{
Effects of Formulation Variables on the Particle Size and Drug Encapsulation of Imatinib-Loaded Solid Lipid Nanoparticles
}

\author{
Biki Gupta, ${ }^{1}$ Bijay Kumar Poudel, ${ }^{1}$ Shiva Pathak, ${ }^{1}$ Jin Wook Tak, ${ }^{1}$ Hee Hyun Lee, ${ }^{1}$ Jee-Heon Jeong, ${ }^{1}$ \\ Han-Gon Choi, ${ }^{2}$ Chul Soon Yong, ${ }^{1,3}$ and Jong Oh Kim ${ }^{1,3}$
}

Received 23 June 2015; accepted 3 August 2015; published online 25 August 2015

\begin{abstract}
Imatinib (IMT), an anticancer agent, inhibits receptor tyrosine kinases and is characterized by poor aqueous solubility, extensive first-pass metabolism, and rapid clearance. The aims of the current study are to prepare imatinib-loaded solid lipid nanoparticles (IMT-SLN) and study the effects of associated formulation variables on particle size and drug encapsulation on IMT-SLN using an experimental design. IMT-SLN was optimized by use of a "combo" approach involving Plackett-Burman design (PBD) and Box-Behnken design (BBD). PBD screening resulted in the determination of organic-toaqueous phase ratio $(\mathrm{O} / \mathrm{A})$, drug-to-lipid ratio (D/L), and amount of Tween ${ }^{\circledR} 20$ (Tw20) as three significant variables for particle size $\left(S_{z}\right)$, drug loading (DL), and encapsulation efficiency (EE) of IMTSLN, which were used for optimization by BBD, yielding an optimized criteria of $\mathrm{O} / \mathrm{A}=0.04, \mathrm{D} / \mathrm{L}=0.03$, and Tw2 $2.50 \% w / v$. The optimized IMT-SLN exhibited monodispersed particles with a size range of $69.0 \pm 0.9 \mathrm{~nm}, \zeta$-potential of $-24.2 \pm 1.2 \mathrm{mV}$, and DL and EE of $2.9 \pm 0.1$ and $97.6 \pm 0.1 \% w / w$, respectively. Results of in vitro release study showed a sustained release pattern, presumably by diffusion and erosion, with a higher release rate at $\mathrm{pH}$ 5.0, compared to $\mathrm{pH}$ 7.4. In conclusion, use of the combo experimental design approach enabled clear understanding of the effects of various formulation variables on IMT-SLN and aided in the preparation of a system which exhibited desirable physicochemical and release characteristics.
\end{abstract}

KEY WORDS: Box-Behnken design; imatinib; Plackett-Burman design; response surface methodology; solid lipid nanoparticle.

\section{INTRODUCTION}

Imatinib (IMT) is an inhibitor of receptor tyrosine kinases with highly potent and specific inhibitory activity against BCRABL fusion gene, platelet-derived growth factor receptor (PDGFR), and c-KIT receptor (1). The highly specific antiproliferative activity of IMT provides strong foundations for its applications to targeted cancer chemotherapy. However, the free base of IMT is practically insoluble in water $(0.001 \mathrm{~g} / 100 \mathrm{ml})$, undergoes extensive first-pass metabolism by cytochrome $\mathrm{P} 450$ enzymes, and shows rapid clearance with an elimination half-life of $\sim 18 \mathrm{~h}$ (2), which lead to poor bioavailability, ultimately limiting its applicability to clinical settings (3). The mesylate salt of IMT, which is marketed by Novartis as Gleevec $®$, has been approved by FDA for the treatment of Philadelphia chromosome-positive chronic myeloid leukemia $\left(\mathrm{Ph}^{+} \mathrm{CML}\right)$, myelodysplastic/ myeloproliferative diseases associated with PDGFR gene rearrange-

\footnotetext{
${ }^{1}$ College of Pharmacy, Yeungnam University, 214-1, Dae-Dong, Gyeongsan, 712-749, South Korea.

${ }^{2}$ College of Pharmacy, Institute of Pharmaceutical Science and Technology, Hanyang University, 55, Hanyangdaehak-ro, Sangnok-gu, Ansan, 426791, South Korea.

${ }^{3}$ To whom correspondence should be addressed. (e-mail: csyong@yu.ac.kr; jongohkim@yu.ac.kr)
}

ments, aggressive systemic mastocytosis, hypereosinophilic syndrome, chronic eosinophilic leukemia, dermatofibrosarcoma protuberans, and malignant gastrointestinal stromal tumors (4).

Solid lipid nanoparticles (SLNs), which are lipid-based nanocarriers composed of a solid lipid core, have been studied extensively in recent years for use in the administration of a large variety of drugs and genetic materials, as monotherapy and in combination, by various routes of administration (514). Such extensive investigations of SLN have been encouraged by the fact that SLN combines the characteristics of different carrier systems, without the various drawbacks often associated with conventional carrier systems. Accordingly, tremendous potential of SLNs to overcome bioavailability issues of drugs exhibiting poor aqueous solubility, extensive first-pass metabolism, and/or rapid renal clearance has been demonstrated. Consequently, SLNs are considered to have great potential for delivery of such medications via oral, parenteral, and other routes of administration $(3,6)$.

Design of experiments (DoE) approach has been an extremely useful tool for defining design spaces around individual or multiple unit operations, which is an important component of control strategy for quality by design (QbD) (15). DoE can be used in construction of a predictive model of the critical response variables, thereby facilitating identification of all potential independent variables and their 
simultaneous systematic and rapid evaluation (16). Optimization strategy for a multivariate process, particularly where the number of variables is extremely large, requires an experimental design consisting of an initial screening (usually by fractional factorial design and Plackett-Burman design), followed by optimization using a response surface design, such as Box-Behnken design and central composite design $(17,18)$.

The current study used a "combo" experimental design approach utilizing Plackett-Burman design and Box-Behnken design for the optimization and preparation of SLN loaded with IMT as an anticancer agent having poor aqueous solubility for characterization of the optimized IMT-SLN and study of its in vitro release characteristics.

\section{MATERIALS AND METHODS}

\section{Materials}

IMT was obtained from LC Laboratories (Woburn, MA, USA). Precirol ${ }^{\circledR}$ ATO 5 (PcA, glyceryl distearate) was obtained from Gattefosse (St. Priest, France), while Tween ${ }^{\circledR} 20$ (TwN, polysorbate 20) and lecithin (LcN) were purchased from Samchun Chemicals (Seoul, Korea) and Junsei (Tokyo, Japan), respectively. Deionized water was freshly prepared as per requirement using a Milli-Q water purification system (Millipore, MA, USA). Other chemicals were reagent grade and were used without further purification.

\section{Methods}

\section{HPLC Analysis for Imatinib}

Method for quantification of IMT was developed by modification of a previously reported HPLC method (19). The HPLC system (Hitachi, Tokyo, Japan) consisted of an L-2130 pump, an L-2200 autosampler, an L-2420 UV-vis detector, and an L-2350 column oven devised using EZChrom elite software (version 318a). An Inertsil $\mathrm{C}_{8}$ column $(250 \times 4.6 \mathrm{~mm}, 5 \mu \mathrm{m}$ particle size; GL Sciences Inc., Tokyo, Japan) was employed under isocratic elution using $0.02 \mathrm{M}$ monobasic potassium phosphate/acetonitrile $(6: 4, v / v)$ as the mobile phase at a flow rate of $1.0 \mathrm{ml} / \mathrm{min}$ and column temperature of $25.0 \pm 1.0^{\circ} \mathrm{C}$. For each analysis, a $20-\mathrm{ml}$ aliquot of the sample was injected and the UV absorbance was measured at a wavelength of $265 \mathrm{~nm}$. The calibration plots exhibited exceptional linearity $\left(R^{2}=0.999\right)$ over a concentration range of $0.1-$ $100 \mu \mathrm{g} / \mathrm{ml}$ and the relative standard deviation (RSD) of the plot over different periods of time was below $3 \%$.

\section{Preparation of IMT-SLN}

IMT-SLN was prepared by hot homogenization method consisting of homogenization and sonication. The method was developed by modification of previously reported methods for preparation of SLN (5-7,20-23). Briefly, the solid lipid (PcA) was dissolved at $70^{\circ} \mathrm{C}$ and mixed with $\mathrm{LcN}$ to constitute the organic phase, to which IMT was added and dissolved by stirring at $50 \mathrm{rpm}$ for $10 \mathrm{~min}$. For the aqueous phase, TwN was dissolved in purified water and heated to $70^{\circ} \mathrm{C}$. The aqueous phase was added to the organic phase using a $10-\mathrm{ml}$ disposable syringe and homogenized using high-performance homogenizer (ULTRA-TURRAX® T25, IKA). The resulting primary emulsion was sonicated using a probe sonicator (Vibra-Cell ${ }^{\mathrm{TM}}$, SONICS) and cooled in an ice bath for $3 \mathrm{~h}$ to obtain IMT-SLN. Blank SLN was prepared using the same procedure, omitting the addition of IMT.

\section{Plackett-Burman Design}

An 11-factor Plackett-Burman design (PBD) at two levels was utilized for initial screening of the main effects of seven variables (Table I) on particle size $\left(S_{z} ; y_{1}\right)$, drug loading (DL; $\left.y_{2}\right)$, and encapsulation efficiency $\left(\mathrm{EE} ; y_{3}\right)$ of IMT-SLN. The lower and upper levels of the seven variables were selected on the basis of prior preliminary experiments. Using Design-Expert ${ }^{\circledR}$ 8.0.7.1 software (Stat-Ease Inc., Minneapolis, MN, USA), 12 experimental runs were generated and were conducted randomly. Variables that exhibited significant main effects by PBD on the specified responses were selected for further optimization of main effects, interaction effects, and quadratic effects by BoxBehnken design.

\section{Box-Behnken Design}

A three-factor Box-Behnken design (BBD) was employed to optimize the main effects, interaction effects, and quadratic effects of the formulation variables on $S_{\mathrm{z}}\left(Y_{1}\right)$, DL $\left(Y_{2}\right)$, and EE $\left(Y_{3}\right)$ of IMT-SLN. The upper and lower levels, along with the central point, of the three variables are shown in Table I. Using Design-Expert ${ }^{\circledR}$ software, 17 experimental runs were generated, which included five center point replicates. The purpose of inclusion of the recommended center point replicates is to ensure that the design gives a good estimate of experimental error and to provide an accurate test for lack of fit. The results for each of the response factors were fitted to a quadratic polynomial model described by the following non-linear equation.

$$
\begin{aligned}
Y= & \beta_{0}+\beta_{1} X_{1}+\beta_{2} X_{2}+\beta_{3} X_{3}+\beta_{4} X_{1} X_{2}+\beta_{5} X_{1} X_{3} \\
& +\beta_{6} X_{2} X_{3}+\beta_{7} X_{1}^{2}+\beta_{8} X_{2}^{2}+\beta_{9} X_{3}^{2}
\end{aligned}
$$

Table I. Variables for Plackett-Burman Design and Box-Behnken

\begin{tabular}{|c|c|c|c|}
\hline \multicolumn{4}{|c|}{ Plackett-Burman design } \\
\hline \multicolumn{2}{|l|}{ Variables } & Lower level & Upper level \\
\hline \multicolumn{2}{|c|}{$x_{1}$ : organic-to-aqueous phase ratio, $\mathrm{O} / \mathrm{A}$} & 0.04 & 0.06 \\
\hline \multicolumn{2}{|c|}{$x_{2}:$ drug-to-lipid ratio, $\mathrm{D} / \mathrm{L}$} & 0.01 & 0.03 \\
\hline \multicolumn{2}{|c|}{$x_{3}:$ amount of lecithin, $\operatorname{Lec}^{a}$} & $2.5 \% w / w$ & $7.5 \% w / w$ \\
\hline \multicolumn{2}{|c|}{$x_{4}$ : amount of Tween 20, Tw $20^{b}$} & $1.5 \% w / v$ & $2.5 \% w / v$ \\
\hline \multicolumn{2}{|c|}{$x_{5}:$ homogenization time, HT } & $5 \mathrm{~min}$ & $15 \min$ \\
\hline \multicolumn{2}{|c|}{$x_{6}:$ sonication time, $\mathrm{ST}$} & $8 \mathrm{~min}$ & $12 \min$ \\
\hline \multicolumn{2}{|c|}{$x_{7}:$ sonication amplitude, SA } & $60 \%$ & $80 \%$ \\
\hline \multicolumn{4}{|c|}{ Box-Behnken design } \\
\hline Variables & Central point & Lower level & Upper level \\
\hline$X_{1}: \mathrm{O} / \mathrm{A}$ & 0.05 & 0.04 & 0.06 \\
\hline$X_{2}: \mathrm{D} / \mathrm{L}$ & 0.02 & 0.01 & 0.03 \\
\hline$X_{3}: \operatorname{Tw} 20^{b}$ & $2.0 \% w / v$ & $1.5 \% w / v$ & $2.5 \% w / v$ \\
\hline
\end{tabular}
Design

${ }^{a}$ Relative to lipid amount

${ }^{b}$ Relative to aqueous phase 


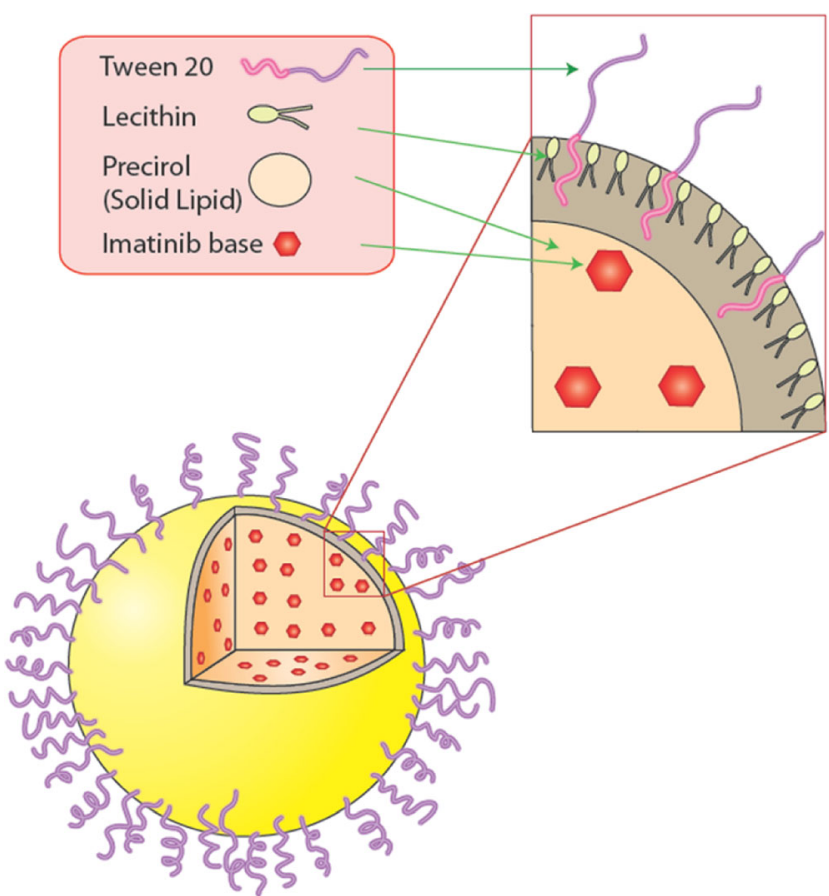

Fig. 1. The scheme of imatinib-loaded solid lipid nanoparticles (IMTSLN)

where $Y$ is the individual response factor or dependent variable; $\beta_{0}-\beta_{9}$ are regression coefficients; and $X_{1}, X_{2}$, and $X_{3}$ are the independent variables.

\section{Optimization Using Desirability Functions}

Following establishment of relationships between dependent and independent variable via model polynomials, all three responses were optimized by use of the desirability functions approach (24) using Design-Expert@ software. Using the desirability functions approach, each response $i$ is associated with its own partial desirability function $\left(d_{i}\right)$, which varies from 0 to 1 depending on the closeness of the response to its target value, i.e., desirability equal to 0 corresponds to the point farthest from the target value while that equal to 1 corresponds to the point closest to the target value.

For maximization of response, the desirability function can be defined as

$$
d_{i}=\left\{\left(Y_{i}-Y_{\min }\right) /\left(Y_{\max }-Y_{\min }\right)\right\}^{s}
$$

For minimization of response, the desirability function can be defined as

$$
d_{i}=\left\{\left(Y_{\max }-Y_{i}\right) /\left(Y_{\max }-Y_{\min }\right)\right\}^{t}
$$

Here, $d_{i}$ represents individual desirability of the response, $Y_{i}$ represents the experimental value of the response, and $Y_{\min }$ and $Y_{\max }$ represent the minimum and maximum acceptable values of the response, respectively. The values of $s$ and $t$ (varying from 0.1 to 10 ) are specified depending on how close the solution is desired from the stated target, i.e., a value of 10 will cause the optimization to seek a solution close to or beyond the stated target. For the purpose of optimization of the IMT-SLN formulation, a value of 1 was specified to both $s$ and $t$.

\section{Particle Size, Polydispersity Index, and $\zeta$-Potential}

The hydrodynamic size, polydispersity index (PDI), and $\zeta$-potential of the IMT-SLN system was determined by dynamic light scattering (DLS) technique using a Nano-S90 ZetaSizer (Malvern Instruments, Worcestershire, UK). The measurements were performed at a fixed scattering angle of $90^{\circ}$ and at an equilibrated temperature of $25^{\circ} \mathrm{C}$. Each sample was adequately diluted with distilled water prior to measurement, and three measurements were performed for each sample.

\section{Drug Loading and Encapsulation Efficiency}

DL and EE were determined by ultracentrifugation. A 2$\mathrm{ml}$ aliquot of IMT-SLN was placed in an Amicon ${ }^{\circledR}$ Ultra-4 $10 \mathrm{~K}$ centrifugal filter device (molecular weight cutoff $10 \mathrm{kDa}$;

\begin{tabular}{|c|c|c|c|c|c|c|c|c|c|c|c|c|c|c|c|}
\hline Run & $x_{1}$ & $x_{2}$ & $x_{3}(\% w / w)$ & $x_{4}(\% w / v)$ & $x_{5}(\min )$ & $x_{6}(\min )$ & $x_{7}(\%)$ & $x_{8}$ & $x_{9}$ & $x_{10}$ & $x_{11}$ & $y_{1}(\mathrm{~nm})$ & PDI & $y_{2}(\% w / w)$ & $y_{3}(\% w / w)$ \\
\hline 1 & 0.04 & 0.03 & 2.5 & 2.5 & 15 & 8 & 80 & 1 & 1 & -1 & -1 & 65.13 & 0.217 & 2.94 & 97.89 \\
\hline 2 & 0.06 & 0.03 & 2.5 & 2.5 & 15 & 12 & 60 & -1 & -1 & 1 & -1 & 109.17 & 0.248 & 2.96 & 98.54 \\
\hline 3 & 0.06 & 0.03 & 7.5 & 1.5 & 5 & 8 & 80 & -1 & 1 & 1 & -1 & 160.33 & 0.236 & 2.95 & 98.35 \\
\hline 4 & 0.04 & 0.03 & 7.5 & 1.5 & 15 & 12 & 80 & -1 & -1 & -1 & 1 & 108.33 & 0.242 & 2.93 & 97.55 \\
\hline 5 & 0.06 & 0.01 & 2.5 & 1.5 & 15 & 8 & 80 & 1 & -1 & 1 & 1 & 169.67 & 0.227 & 0.95 & 95.28 \\
\hline 6 & 0.06 & 0.01 & 7.5 & 2.5 & 15 & 8 & 60 & -1 & 1 & -1 & 1 & 119.57 & 0.239 & 0.98 & 97.74 \\
\hline 7 & 0.04 & 0.01 & 2.5 & 1.5 & 5 & 8 & 60 & -1 & -1 & -1 & -1 & 126.70 & 0.232 & 0.96 & 95.93 \\
\hline 8 & 0.04 & 0.03 & 7.5 & 2.5 & 5 & 8 & 60 & 1 & -1 & 1 & 1 & 83.33 & 0.260 & 2.94 & 98.14 \\
\hline 9 & 0.06 & 0.01 & 7.5 & 2.5 & 5 & 12 & 80 & 1 & -1 & -1 & -1 & 102.80 & 0.222 & 0.96 & 95.50 \\
\hline 10 & 0.04 & 0.01 & 2.5 & 2.5 & 5 & 12 & 80 & -1 & 1 & 1 & 1 & 61.19 & 0.206 & 0.97 & 96.59 \\
\hline 11 & 0.06 & 0.03 & 2.5 & 1.5 & 5 & 12 & 60 & 1 & 1 & -1 & 1 & 167.83 & 0.232 & 2.94 & 98.07 \\
\hline 12 & 0.04 & 0.01 & 7.5 & 1.5 & 15 & 12 & 60 & 1 & 1 & 1 & -1 & 114.93 & 0.220 & 0.96 & 96.03 \\
\hline
\end{tabular}

Table II. Plackett-Burman Design Matrix and Observed Response Values

$x_{1}$ organic-to-aqueous phase ratio (O/A); $x_{2}$ drug-to-lipid ratio (D/L); $x_{3}$ amount of lecithin (Lec); $x_{4}$ amount of Tween ${ }^{\circledR} 20$ (Tw20); $x_{5}$ homogenization time (HT); $x_{6}$ sonication time $(\mathrm{ST}) ; x_{7}$ sonication amplitude $(\mathrm{SA}) ; x_{8}, x_{9}, x_{10}$, and $x_{11}$ dummy variables; $y_{1}$ particle size $\left(S_{\mathrm{z}}\right)$; $y_{2}$ drug loading (DL); $y_{3}$ encapsulation efficiency (EE) 
Merck Millipore Ltd., Ireland), centrifuged at $2000 \mathrm{~g}$ for $10 \mathrm{~min}$, and the filtrate was analyzed for free drug by HPLC quantification as described in the previous section. DL and EE were calculated using the following formulae:

$$
\operatorname{DL}(\%)=\left\{\left(W_{\mathrm{T}}-W_{\mathrm{U}}\right) /\left(W_{\mathrm{L}}+W_{\mathrm{T}}-W_{\mathrm{U}}\right)\right\} * 100
$$$$
\mathrm{EE}(\%)=\left\{\left(W_{\mathrm{T}}-W_{\mathrm{U}}\right) / W_{\mathrm{T}}\right\} * 100
$$

Here, $W_{\mathrm{T}}, W_{\mathrm{U}}$, and $W_{\mathrm{L}}$ denote weight of initially added total drug, weight of unbound drug, and weight of total lipid, respectively.

\section{Transmission Electron Microscopy}

Transmission electron microscopy (TEM) was employed to examine the size and morphology of the IMT-SLN. A drop of the formulation was deposited onto a copper grid coated with a carbon film, and the particles were subjected to negative staining by $2 \% w / v$ phosphotungstic acid. The sample was then appropriately dried under mild to moderate infrared radiation and observed under an $\mathrm{H} 7600$ transmission electron microscope (Hitachi, Tokyo, Japan).

\section{Freeze-Drying}

IMT-SLN, along with blank SLN, was pre-frozen at $-70^{\circ} \mathrm{C}$ for $6 \mathrm{~h}$ and subsequently lyophilized (freeze-dried) at $-40^{\circ} \mathrm{C}$ for $24 \mathrm{~h}$ using an EYELA ${ }^{\circledR}$ Freeze Dryer (Tokyo Rikakikai Co. Ltd., Tokyo, Japan). Upon completion of freeze-drying, the samples were allowed to dry for an additional $12 \mathrm{~h}$ at $20^{\circ} \mathrm{C}$.

\section{Differential Scanning Calorimetry}

Freeze-dried IMT-SLN and blank SLN were used for solid-state characterization by differential scanning calorimetry (DSC). A DSC-Q200 differential scanning calorimeter (TA Instruments, New Castle, DE, USA) was used for observation of thermal characteristics of IMT-SLN, blank SLN, and IMT. DSC scans were performed by heating all samples from 20 to $250^{\circ} \mathrm{C}$, at a heating rate of $20^{\circ} \mathrm{C} / \mathrm{min}$ in a dynamic nitrogen atmosphere.

\section{X-Ray Diffraction}

A vertical goniometer and X-ray diffractometer (X'pert PRO MPD diffractometer, Almelo, The Netherlands) was used to observe the X-ray diffraction (XRD) patterns of freeze-dried IMT-SLN, blank SLN, and IMT. The diffractometer measured Ni-filtered $\mathrm{CuK} \alpha$-radiation (voltage $40 \mathrm{kV}$; current $30 \mathrm{~mA}$ ) scattered in the crystalline regions of the sample. XRD scans were performed over a diffraction angle $(2 \theta)$ range of $10-60^{\circ}$ and a scanning rate of $5 \% \mathrm{~min}$.

\section{Physical Stability Study}

Physical stability of the IMT-SLN system was assessed by recording changes in $S_{\mathrm{z}}$, PDI, and EE over a period of 60 days upon storage at two different temperatures, 4 and $22^{\circ} \mathrm{C}$. An aliquot of the sample was taken after $0,1,2,4,7,15,30$, and
60 days of storage and $S_{\mathrm{z}} / \mathrm{PDI}$ and EE were determined by DLS characterization and centrifugation method, respectively.

\section{In Vitro Release Study}

In vitro release study was performed by dialysis method at $\mathrm{pH} 7.4$ and $\mathrm{pH}$ 5.0, using phosphate-buffered saline (PBS) and acetate buffer solution (ABS) as respective release media. Briefly, $2 \mathrm{ml}$ aliquots of IMT-SLN (equivalent to $2.5 \mathrm{mg}$ of IMT) were placed in dialysis bags (molecular weight cutoff
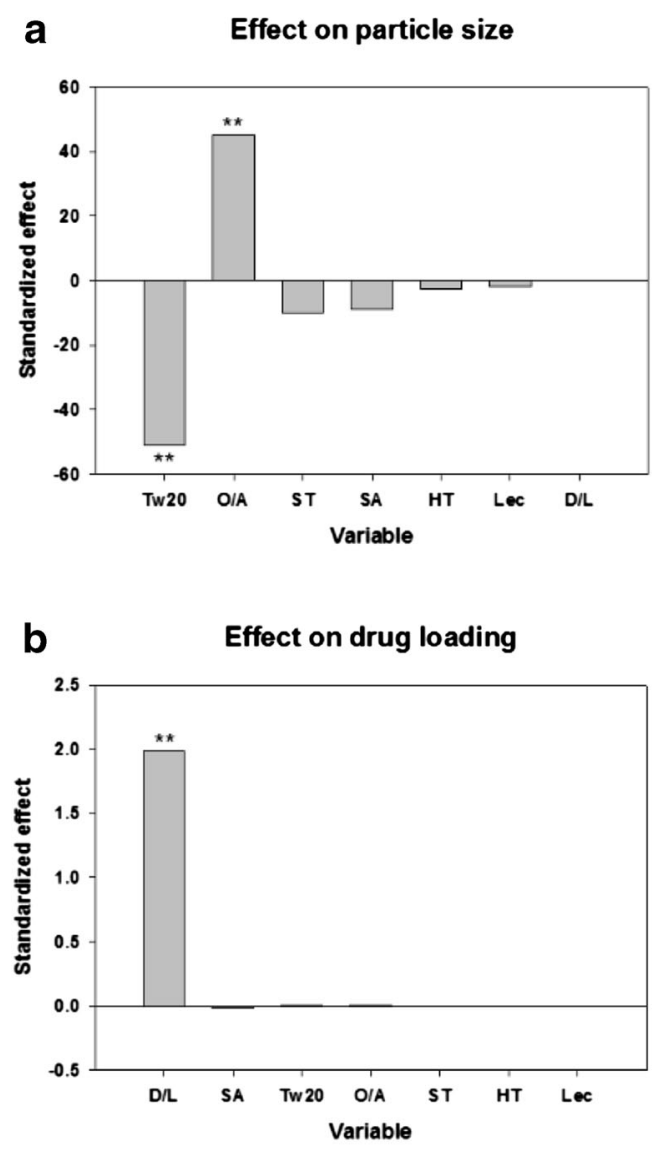

C Effect on encapsulation efficiency

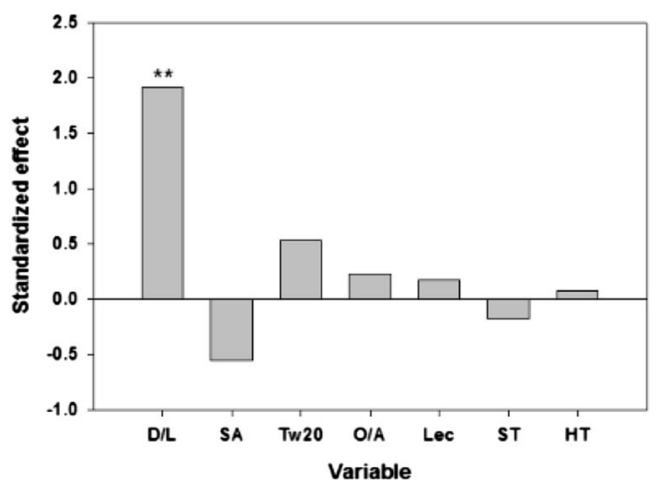

Fig. 2. Plackett-Burman Design: effects of different variables on particle size (a), drug loading (b), and encapsulation efficiency (c). **Significant at $p<0.001$. $O / A$ organic-to-aqueous phase ratio, $D / L$ drug-tolipid ratio, Tw20 amount of Tween ${ }^{\circledR} 20$, Lec amount of lecithin, $H T$ homogenization time, $S T$ sonication time, $S A$ sonication amplitude 
Table III. Box-Behnken Design Matrix and Observed Response Values

\begin{tabular}{|c|c|c|c|c|c|c|c|}
\hline Run & $X_{1}$ & $X_{2}$ & $X_{3}(\% w / v)$ & $Y_{1}(\mathrm{~nm})$ & PDI & $Y_{2}(\% w / w)$ & $Y_{3}(\% w / w)$ \\
\hline 1 & 0.05 & 0.02 & 2.0 & 108.00 & 0.221 & 1.95 & 97.38 \\
\hline 2 & 0.04 & 0.02 & 1.5 & 112.60 & 0.220 & 1.92 & 96.24 \\
\hline 3 & 0.05 & 0.03 & 1.5 & 138.23 & 0.218 & 2.92 & 97.47 \\
\hline 4 & 0.06 & 0.01 & 2.0 & 126.27 & 0.207 & 0.96 & 95.52 \\
\hline 5 & 0.05 & 0.02 & 2.0 & 102.33 & 0.220 & 1.94 & 97.18 \\
\hline 6 & 0.06 & 0.02 & 2.5 & 104.60 & 0.211 & 1.94 & 96.99 \\
\hline 7 & 0.04 & 0.02 & 2.5 & 70.80 & 0.208 & 1.95 & 97.70 \\
\hline 8 & 0.04 & 0.03 & 2.0 & 89.08 & 0.225 & 2.94 & 97.91 \\
\hline 9 & 0.04 & 0.01 & 2.0 & 89.72 & 0.205 & 0.98 & 97.60 \\
\hline 10 & 0.05 & 0.03 & 2.5 & 88.55 & 0.223 & 2.95 & 98.28 \\
\hline 11 & 0.05 & 0.02 & 2.0 & 106.67 & 0.220 & 1.95 & 97.61 \\
\hline 12 & 0.06 & 0.02 & 1.5 & 156.37 & 0.210 & 1.95 & 97.55 \\
\hline 13 & 0.05 & 0.01 & 1.5 & 139.87 & 0.237 & 0.96 & 95.59 \\
\hline 14 & 0.06 & 0.03 & 2.0 & 134.07 & 0.256 & 2.96 & 98.58 \\
\hline 15 & 0.05 & 0.02 & 2.0 & 110.13 & 0.231 & 1.96 & 98.01 \\
\hline 16 & 0.05 & 0.02 & 2.0 & 109.70 & 0.238 & 1.95 & 97.62 \\
\hline 17 & 0.05 & 0.01 & 2.5 & 91.10 & 0.213 & 0.96 & 96.24 \\
\hline
\end{tabular}

$X_{1}$ organic-to-aqueous phase ratio $(\mathrm{O} / \mathrm{A}), X_{2}$ drug-to-lipid ratio $(\mathrm{D} / \mathrm{L}), X_{3}$ amount of Tween ${ }^{\circledR} 20(\mathrm{Tw} 20) ; Y_{1}$ particle size $\left(S_{\mathrm{z}}\right), Y_{2}$ drug loading (DL), $Y_{3}$ encapsulation efficiency (EE)

Table IV. ANOVA for the Response Surface Reduced Quadratic Models

\begin{tabular}{|c|c|c|c|c|c|}
\hline Response & Source & Sum of squares & Mean square & $F$ value & $p$ value \\
\hline \multirow[t]{10}{*}{$Y_{1}$ : particle size } & Model & 7887.80 & 1577.56 & 166.70 & $<0.0001$ \\
\hline & $X_{1}: \mathrm{O} / \mathrm{A}$ & 3164.37 & 3164.37 & 334.37 & $<0.0001$ \\
\hline & $X_{2}: \mathrm{D} / \mathrm{L}$ & 1.11 & 1.11 & 0.12 & 0.7390 \\
\hline & $X_{3}:$ Tw20 & 4608.64 & 4608.64 & 486.99 & $<0.0001$ \\
\hline & $X_{2}^{2}$ & 34.48 & 34.48 & 3.64 & 0.0827 \\
\hline & $X_{3}^{2}$ & 73.27 & 73.27 & 7.74 & 0.0178 \\
\hline & Residual & 104.10 & 9.46 & & \\
\hline & Lack of fit & 64.77 & 9.25 & 0.94 & $0.5587 *$ \\
\hline & Pure error & 39.32 & 9.83 & & \\
\hline & Cor total & 7991.90 & & & \\
\hline \multirow[t]{12}{*}{$Y_{2}$ : drug loading } & Model & 7.84 & 1.12 & $35,093.73$ & $<0.0001$ \\
\hline & $X_{1}: \mathrm{O} / \mathrm{A}$ & $1.52 \times 10^{-5}$ & $1.52 \times 10^{-5}$ & 0.48 & 0.5075 \\
\hline & $X_{2}: \mathrm{D} / \mathrm{L}$ & 7.84 & 7.84 & $2.456 \times 10^{5}$ & $<0.0001$ \\
\hline & $X_{3}:$ Tw20 & $2.975 \times 10^{-4}$ & $2.975 \times 10^{-4}$ & 9.32 & 0.0137 \\
\hline & $X_{1} X_{2}$ & $4.145 \times 10^{-4}$ & $4.145 \times 10^{-4}$ & 12.99 & 0.0057 \\
\hline & $X_{1} X_{3}$ & $4.058-10^{-4}$ & $4.058 \times 10^{-4}$ & 12.72 & 0.0061 \\
\hline & $X_{2}^{2}$ & $1.176 \times 10^{-4}$ & $1.176 \times 10^{-4}$ & 3.69 & 0.0871 \\
\hline & $X_{3}^{2}$ & $3.267 \times 10^{-4}$ & $3.267 \times 10^{-4}$ & 10.24 & 0.0108 \\
\hline & Residual & $2.871 \times 10^{-4}$ & $3.19 \times 10^{-5}$ & & \\
\hline & Lack of fit & $1.341 \times 10^{-4}$ & $2.683 \times 10^{-5}$ & 0.70 & $0.6522 *$ \\
\hline & Pure error & $1.53 \times 10^{-4}$ & $3.825 \times 10^{-5}$ & & \\
\hline & Cor total & 7.84 & & & \\
\hline \multirow{11}{*}{$Y_{3}:$ encapsulation efficiency } & Model & 11.31 & 1.88 & 16.557 & 0.0001 \\
\hline & $X_{1}: \mathrm{O} / \mathrm{A}$ & 0.084 & 0.084 & 0.74 & 0.4093 \\
\hline & $X_{2}: \mathrm{D} / \mathrm{L}$ & 6.64 & 6.64 & 58.39 & $<0.0001$ \\
\hline & $X_{3}:$ Tw20 & 0.69 & 0.69 & 6.10 & 0.0331 \\
\hline & $X_{1} X_{2}$ & 1.88 & 1.88 & 16.57 & 0.0022 \\
\hline & $X_{1} X_{3}$ & 1.01 & 1.01 & 8.92 & 0.0136 \\
\hline & $X_{3}^{2}$ & 0.99 & 0.99 & 8.72 & 0.0145 \\
\hline & Residual & 1.14 & 0.11 & & \\
\hline & Lack of fit & 0.75 & 0.13 & 1.31 & $0.4129 *$ \\
\hline & Pure error & 0.38 & 0.096 & & \\
\hline & Cor total & 12.44 & & & \\
\hline
\end{tabular}

Insignificant factors were excluded from the model to obtain a better fit

*Not significant at $p<0.1$ 
Table V. Correlation Coefficients for the Response Surface Reduced Quadratic Models

\begin{tabular}{lcccc}
\hline Response & $R^{2}$ & Adjusted $R^{2}$ & Predicted $R^{2}$ & Adeq precision \\
\hline$Y_{1}$ & 0.9870 & 0.9811 & 0.9678 & 48.030 \\
$Y_{2}$ & 1.0000 & 0.9999 & 0.9999 & 517.667 \\
$Y_{3}$ & 0.9086 & 0.8538 & 0.5898 & 14.764 \\
\hline
\end{tabular}

$3.5 \mathrm{kD}$ ), previously hydrated overnight in respective release media. The dialysis bags were clipped at both ends and then kept in a USP Type II dissolution apparatus containing $400 \mathrm{ml}$ of respective release media (with $1 \% w / v$ TwN), maintained at a temperature of $37 \pm 0.5^{\circ} \mathrm{C}$. The paddles were operated at $50 \mathrm{rpm}$, and $2 \mathrm{ml}$ of the medium was withdrawn at defined time intervals and replaced with the same amount of fresh release medium each time. HPLC was performed to determine the content of IMT in each sample.

\section{Statistical Analysis}

All data were expressed as mean \pm SD $(n=3)$. Data obtained from the experiments designed using Box-Behnken design were analyzed by ANOVA, lack-of-fit tests, and multiple correlation coefficients. Student's $t$ test was used to test the statistical significance wherever applicable.

\section{RESULTS AND DISCUSSION}

\section{Preparation of IMT-SLN}

Hot homogenization technique was employed for preparation of IMT-SLN, which involved homogenization and subsequent probe sonication. While the solid lipid core was composed of glyceryl distearate (PcA), LcN was used as a hydrophobic emulsifier. In addition, TwN (polysorbate 20), a polyoxyethylene derivative, was used as a hydrophilic surfactant. The hydrophilic polyoxyethylene polymer, along with the hydrophobic LcN, confers a highly protective amphiphilic stealth outer cover to the SLN, which provides longcirculating properties to the carrier system by evading clearance by the reticuloendothelial system $(25,26)$. The longcirculating carriers act as circulating drug reservoirs in blood and aid passive targeting. These characteristics are highly beneficial for cancer chemotherapy (27). The scheme of the IMT-SLN system is shown in Fig. 1.

\section{Plackett-Burman Design}

PBD was used for screening variables among the lot which showed no significant influence on SLN characteristics. PBD is a two-level screening design, which enables the examination of a relatively large number of variables in a relatively small number of experiments (17). It is recommended for study of the main effects, assuming absence of interaction effects. It is also useful for ruggedness testing, where the aim is to determine whether the given factors have little or no impact on a given response. An 11-factor PBD was employed to study the main effects of the seven independent variables, employing four dummy variables to make up the 11 factors. The PBD matrix generated using Design-Expert ${ }^{\circledR}$ software, along with the observed response values, has been shown in Table II. The respective PDI for each of the 12 runs, which were highly acceptable $(<0.300)$ in all cases, are also included in the table. The effects of the seven independent variables on $S_{\mathrm{z}}, \mathrm{DL}$, and EE are illustrated in Fig. 2. As evident from the illustration, amount of Tween ${ }^{\circledR} 20$ (Tw20) and organic-to-aqueous phase ratio $(\mathrm{O} / \mathrm{A})$ showed significant main effects on $S_{\mathrm{z}}$, while drug-to-lipid ratio (D/L) showed significant main effects on DL and EE. Based on this observation, O/A, $\mathrm{D} / \mathrm{L}$, and Tw20 were selected as three variables for further optimization by employing Box-Behnken design.

\section{Box-Behnken Design}

The most significant factors, usually after determination from a screening experiment or from experience, are subjected to detailed examination using a suitable response surface design approach to obtain optimal conditions for each factor (17). Therefore, BBD was used to optimize the main effects, interaction effects, and quadratic effects of three independent variables, viz. O/A $\left(X_{1}\right), \mathrm{D} / \mathrm{L}\left(X_{2}\right)$, and Tw20 $\left(X_{3}\right)$ on three response variables, $S_{\mathrm{z}}\left(Y_{1}\right)$, DL $\left(Y_{2}\right)$, and $\operatorname{EE}\left(Y_{3}\right)$. The 17 experimental runs, generated using Design-Expert® software, were as represented by the BBD matrix in Table III. The runs, as entailed by the BBD matrix, were conducted simultaneously. The corresponding values of the response variables observed were as summarized alongside each run in the BBD matrix shown in Table III, which also includes the corresponding PDI values. Each response was individually fitted to a second-order quadratic model. Various statistical parameters

Table VI. Factor Coefficient Estimates and Corresponding Standard Error Values

\begin{tabular}{|c|c|c|c|c|c|c|}
\hline \multirow[t]{2}{*}{ Factor } & \multicolumn{2}{|c|}{$Y_{1}$} & \multicolumn{2}{|c|}{$Y_{2}$} & \multicolumn{2}{|c|}{$Y_{3}$} \\
\hline & Coeff. estimate & Std. error & Coeff. estimate & Std. error & Coeff. estimate & Std. error \\
\hline Intercept & 107.17 & 1.22 & 1.95 & $2.24 \times 10^{-3}$ & 97.49 & 0.11 \\
\hline$X_{1}$ & 19.89 & 1.09 & $1.38 \times 10^{-3}$ & $2.00 \times 10^{-3}$ & -0.01 & 0.12 \\
\hline$X_{2}$ & 0.37 & 1.09 & 0.99 & $2.00 \times 10^{-3}$ & 0.91 & 0.12 \\
\hline$X_{3}$ & -24.00 & 1.09 & $6.10 \times 10^{-3}$ & $2.00 \times 10^{-3}$ & 0.29 & 0.12 \\
\hline$X_{1} X_{2}$ & - & - & 0.010 & $2.82 \times 10^{-3}$ & 0.69 & 0.17 \\
\hline$X_{1} X_{3}$ & - & - & -0.010 & $2.82 \times 10^{-3}$ & -0.50 & 0.17 \\
\hline$X_{2}^{2}$ & 2.86 & 1.50 & $5.28 \times 10^{-3}$ & $2.75 \times 10^{-3}$ & - & - \\
\hline$X_{3}^{2}$ & 4.17 & 1.50 & $-8.80 \times 10^{-3}$ & $2.75 \times 10^{-3}$ & -0.48 & 0.16 \\
\hline
\end{tabular}



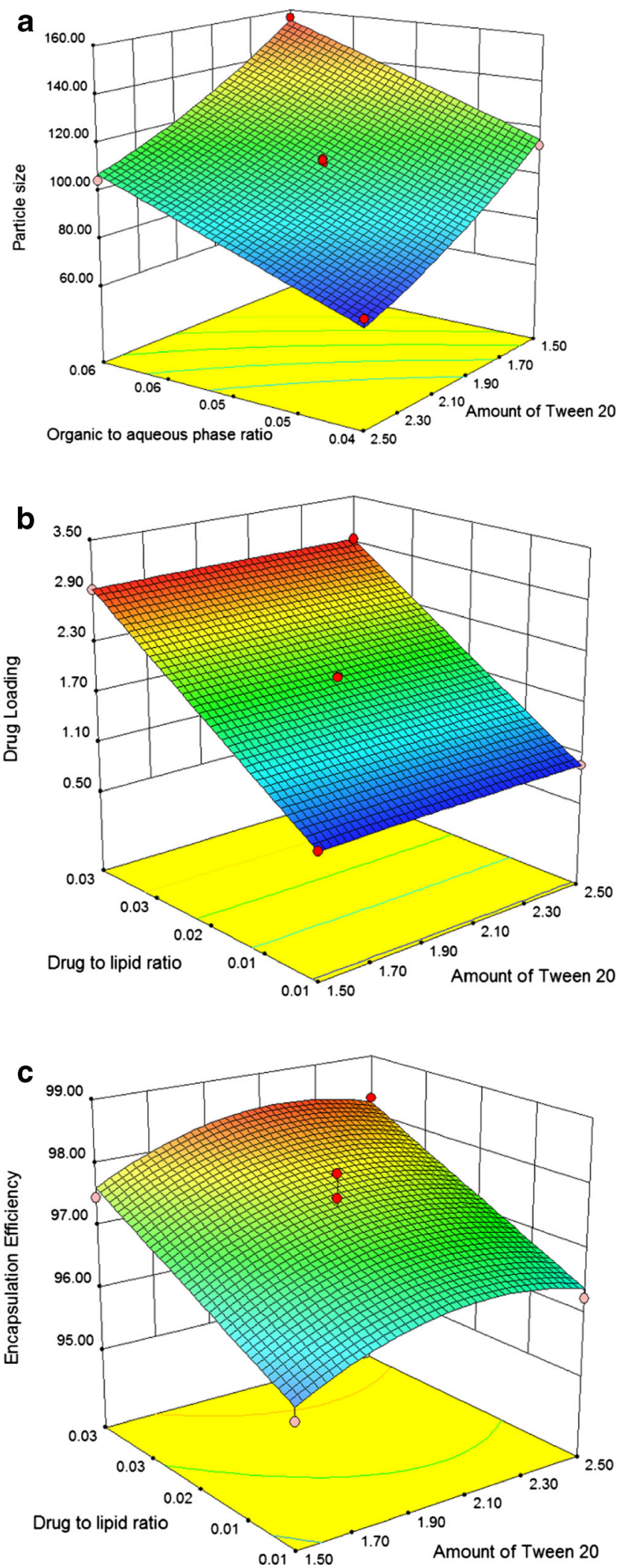

Fig. 3. Box-Behnken Design: 3-D response surface plots showing a effects of organic-to-aqueous phase ratio and amount of Tween ${ }^{\circledR} 20$ on particle size, $\mathbf{b}$ effects of drug-to-lipid ratio and amount of Tween ${ }^{\circledR}$ 20 on drug loading, and $\mathbf{c}$ effects of drug-to-lipid ratio and amount of Tween ${ }^{\circledR} 20$ on encapsulation efficiency provided by software, comprising ANOVA, lack-of-fit tests, and multiple correlation coefficients $\left(R^{2}\right)$ tests, were used to determine the model significance. Results of such statistical evaluations are shown in Tables IV and V.

At a significance level of $5 \%$, models corresponding to all three responses, $Y_{1}, Y_{2}$, and $Y_{3}$, showed a good fit to the quadratic model, as can be confirmed by their respective model $p$ values shown in Table IV. In addition, the lack of fit for each model was insignificant ( $p$ value $>0.1$ ). Insignificant lack of fit is desirable to reaffirm that a model exhibits good fitting to the corresponding response. The correlation coefficient $\left(R^{2}\right)$ value and the adequate precision value, a measure of signal to noise ratio, were also adequately large for each of the three responses (Table V). The significant individual model terms are also included in Table IV. The factor terms $X_{2}^{2}$ and $X_{3}{ }^{2}$ indicate quadratic effects while $X_{1} X_{2}$ and $X_{1} X_{3}$ indicate interaction effects. To ensure a better fit, factor terms representative of interaction and quadratic effects insignificant at $p<0.1$ have been excluded from the model. From Table IV, we can observe that O/A $\left(X_{1}\right)$ and Tw20 $\left(X_{3}\right)$ exhibit significant main effects on $S_{z}$ $\left(Y_{1}\right)$ at $p<0.05$, with Tw20 having a slightly more prominent main effect on $S_{\mathrm{z}}$ than $\mathrm{O} / \mathrm{A}$ as indicated by its relatively larger $F$ value. Tw20 also exhibits significant quadratic effects $\left(X_{3}^{2}\right)$ on $S_{\mathrm{Z}}$ at $p<0.05$. Similarly, D/L $\left(X_{2}\right)$ and Tw20 $\left(X_{3}\right)$ exhibited significant main effects on DL $\left(Y_{2}\right)$ as well as $\operatorname{EE~}\left(Y_{3}\right)$ at $p<0.05$. O/A-D/L $\left(X_{1} X_{2}\right)$ and O/A-Tw20 $\left(X_{1} X_{3}\right)$ exhibited significant interaction effects, while Tw20 $\left(X_{3}^{2}\right)$ exhibited significant quadratic effects on both DL and EE at $p<0.05$.

Factor coefficients representing quantitative effects of the independent variables $X_{1}, X_{2}$, and $X_{3}$ on the responses $Y_{1}, Y_{2}$, and $Y_{3}$ are shown in Table VI, which, upon consideration along with the findings of the prior statistical evaluations, prompt the conclusion that $X_{1}$ had a significant positive main effect and $X_{3}$ had a significant negative main effect on $Y_{1}$, while $X_{2}$ and $X_{3}$ had significant positive main effects on both $Y_{2}$ and $Y_{3} . X_{1}-X_{2}$ had significant positive interaction effects on both $Y_{2}$ and $Y_{3}$, while $X_{1}-X_{3}$ had significant negative interaction effects on both $Y_{2}$ and $Y_{3} . X_{3}$ had a significant positive quadratic effect on $Y_{1}$, while it had a significant negative quadratic effect on $Y_{2}$ and $Y_{3}$. All observations were in good agreement with those of previously reported studies (28-30).

\section{Response Surface Analysis}

Response surface analysis, aided by three-dimensional response surface plots (Fig. 3), was employed to further elucidate the relationships between the dependent and

Table VII. Predicted and Observed Response Values for Optimized Formulation

\begin{tabular}{lccc}
\hline Response & Prediction & $\begin{array}{l}\text { Standard } \\
\text { error of } \\
\text { prediction }\end{array}$ & \\
\hline & & Observation $^{\text {a }}$ & \\
\hline$Y_{1}$ : particle size $(\mathrm{nm})$ & 70.80 & 3.83 & $69.04 \pm 0.94^{b}$ \\
$Y_{2}$ : drug loading $(\% w / w)$ & 2.94 & 0.01 & $2.93 \pm 0.002^{b}$ \\
$Y_{3}:$ encapsulation efficiency & 98.13 & 0.58 & $97.60 \pm 0.05^{b}$ \\
$(\% w / w)$ & & & \\
\hline
\end{tabular}

${ }^{a}$ Values are expressed as mean $\pm \mathrm{SD}(n=3)$

${ }^{b}$ No significant difference from the predicted response values at $p<0.05$ 
independent variables deemed statistically significant. A 3-D response surface plot is a graphical representation of a regression equation exhibiting changes in response variable against two independent variables at a time, keeping the other variables fixed at their middle levels. Figure 3a depicts the effects of O/A and Tw20 on $S_{\mathrm{z}}$, where $S_{\mathrm{z}}$ increases with an increase in $\mathrm{O} / \mathrm{A}$ while it decreases with an increase in Tw20. This was in good agreement with previous reports $(28,30,31)$. The reason for increase in $S_{\mathrm{z}}$ with increase in $\mathrm{O} / \mathrm{A}$ could be that viscosity of the dispersion increases with increase in lipid fraction, leading to higher surface tension and ultimately larger particle size. The reason for decrease in $S_{\mathrm{z}}$ as a result of increased Tw20 could be that higher content of surfactant reduces the interfacial tension more effectively, thereby resulting in small-

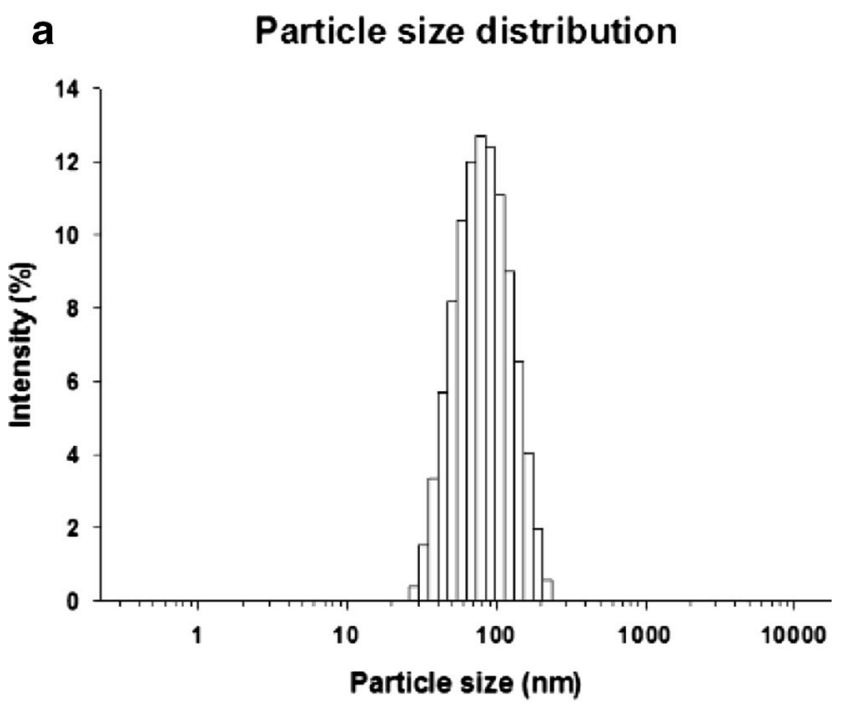

b

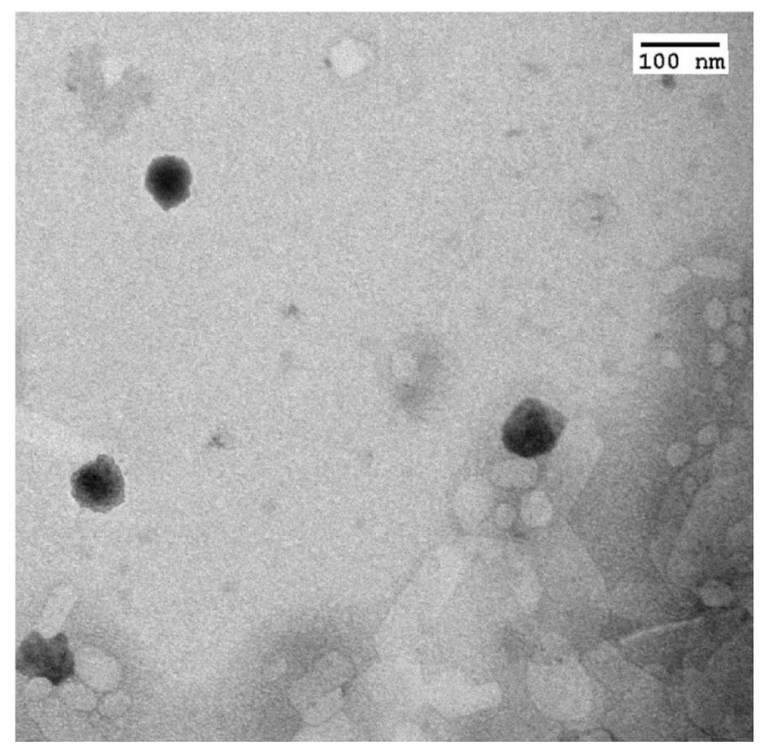

Fig. 4. Characterization of the IMT-SLN system: a particle size distribution and $\mathbf{b}$ transmission electron microscopy (TEM) imaging er particle sizes (28). Figure $3 \mathrm{~b}$ depicts the effects of $\mathrm{D} / \mathrm{L}$ and Tw20 on DL, where DL increases with an increase in $\mathrm{D} / \mathrm{L}$, in line with previous study reports $(28,29,31)$. Figure $3 \mathrm{c}$ depicts the effects of D/L and Tw20 on EE, where with an increase in D/L, EE also increases; with an increase in Tw20, EE initially increases and then decreases. The results of EE were also in good agreement with those of previously reported studies (28).

\section{Optimization Using Desirability Function}

Generation of model polynomials to establish the relationship between dependent and independent variables was followed by subsequent optimization of the three responses using a desirability function approach for optimization of multiple responses introduced by Derringer and Suich. The three responses $Y_{1}, Y_{2}$, and $Y_{3}$ were transformed into individual desirability $d_{1}, d_{2}$, and $d_{3}$, respectively. All three variables, $X_{1}, X_{2}$, and $X_{3}$, were set in range and goals were defined for each response. The goal defined for $Y_{1}$ was minimization, while the goal for $Y_{2}$ and $Y_{3}$ was maximization. Equal weights and importance were assigned to each of the three responses. Consequently, a number of solutions, ordered by their desirability value, were generated. The solution showing the

a

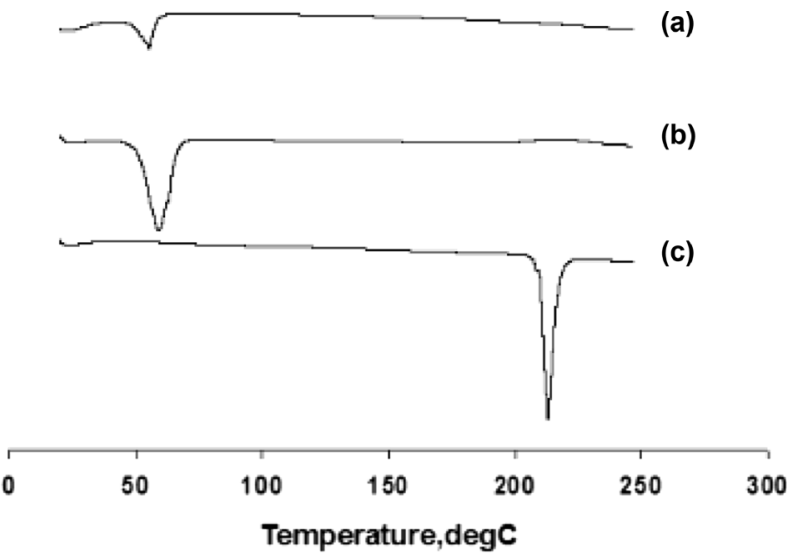

b
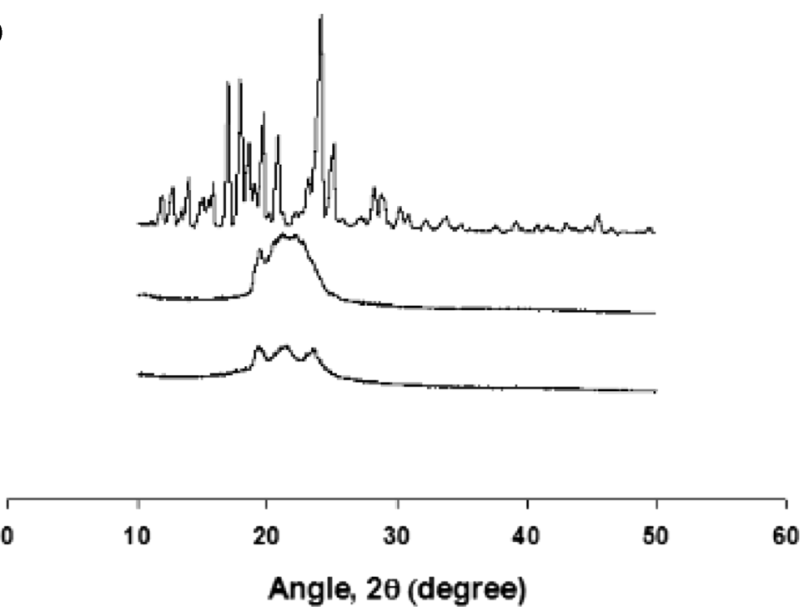

Fig. 5. Characterization of the IMT-SLN system: a differential scanning calorimetry (DSC) thermograms and $\mathbf{b}$ X-ray diffraction (XRD) patterns. $a$ IMT-SLN, $b$ Precirol ATO5, and $c$ free IMT 
Table VIII. Physical Stability of IMT-Loaded SLN System After Storage

\begin{tabular}{|c|c|c|c|c|c|c|}
\hline \multirow[t]{2}{*}{ Day } & \multicolumn{3}{|c|}{ Upon storage at $4^{\circ} \mathrm{C}$} & \multicolumn{3}{|c|}{ Upon storage at $22^{\circ} \mathrm{C}$} \\
\hline & Particle size, nm & PDI & $\mathrm{EE}, \% w / v$ & Particle size, $\mathrm{nm}$ & PDI & $\mathrm{EE}, \% w / v$ \\
\hline 0 & $69.04 \pm 0.94$ & $0.219 \pm 0.015$ & $97.60 \pm 0.05$ & $69.04 \pm 0.94$ & $0.219 \pm 0.015$ & $97.60 \pm 0.05$ \\
\hline 1 & $69.42 \pm 0.74$ & $0.211 \pm 0.014$ & $97.60 \pm 0.06$ & $70.18 \pm 0.44$ & $0.223 \pm 0.014$ & $97.49 \pm 0.05$ \\
\hline 2 & $69.82 \pm 0.44$ & $0.220 \pm 0.015$ & $97.58 \pm 0.06$ & $70.67 \pm 0.57$ & $0.224 \pm 0.023$ & $96.47 \pm 0.01$ \\
\hline 4 & $70.49 \pm 0.45$ & $0.225 \pm 0.024$ & $97.57 \pm 0.03$ & $72.01 \pm 0.80$ & $0.246 \pm 0.024$ & $95.30 \pm 0.08$ \\
\hline 7 & $70.73 \pm 0.41$ & $0.235 \pm 0.010$ & $97.51 \pm 0.02$ & $75.68 \pm 0.39$ & $0.283 \pm 0.040$ & $95.08 \pm 0.08$ \\
\hline 15 & $70.96 \pm 0.93$ & $0.237 \pm 0.006$ & $97.44 \pm 0.07$ & $86.28 \pm 0.28$ & $0.304 \pm 0.057$ & $93.83 \pm 0.15$ \\
\hline 30 & $71.55 \pm 1.01$ & $0.233 \pm 0.005$ & $97.36 \pm 0.05$ & $94.80 \pm 0.19$ & $0.297 \pm 0.029$ & $92.33 \pm 0.09$ \\
\hline 60 & $72.43 \pm 0.78$ & $0.234 \pm 0.008$ & $97.15 \pm 0.09$ & $109.76 \pm 0.78$ & $0.319 \pm 0.042$ & $91.17 \pm 0.32$ \\
\hline
\end{tabular}

All observed values are expressed as mean \pm SD

$P D I$ polydispersity index, $E E$ encapsulation efficiency

maximum desirability value $(D=0.947)$ was selected as the most optimum, where O/A, D/L, and Tw20 were 0.04, 0.03, and $2.50 \% \mathrm{w} / \mathrm{v}$, respectively. To validate the prediction capability of the model, three optimized formulations with the above "most optimum" factor combination were prepared, and $S_{\mathrm{z}}, \mathrm{DL}$, and EE for each formulation were evaluated. Tabulation of the observed responses along with the predicted response values is shown in Table VII. As shown in Table VII, all of the observed response values were in good agreement with the predicted values, with reference to the standard error of prediction. This indicates that the experimental design approach closely predicted the relationships between the dependent and independent variables and was helpful in establishing a model for successful optimization of the IMT-SLN system.

\section{Characterization of IMT-SLN}

The particle size distribution of the optimized IMT-SLN system is shown in Fig. 4a. The particles showed an excellent size of $69.0 \pm 0.9 \mathrm{~nm}$, with PDI within an acceptable range of $0.219 \pm 0.015$. The $\zeta$-potential of the optimized system, which is indicative of surface charge of the particles, was $-24.2 \pm 1.2$, and DL and EE were 2.9 \pm 0.1 and $97.6 \pm 0.1$, respectively. TEM images of the IMT-SLN system are shown in Fig. 4b, which clearly illustrate that the particles were distinct and spherical and had an average size of approximately $70 \mathrm{~nm}$, consistent with the data obtained by DLS characterization. The spectacularly small particle size of IMT-SLN was potentially advantageous for passive tumor targeting of the drug specifically to the tumor tissues by enhanced permeability and retention (EPR) effect. Nanocarriers with particle sizes below $200 \mathrm{~nm}$ are reported to be ideally suitable for exploitation of the EPR effect $(32,33)$.

DSC and XRD constituted the solid-state characterization of IMT-SLN. As illustrated in Fig. 5a, a sharp endothermic peak was observed in the region of $211-216^{\circ} \mathrm{C}$ for free IMT, which represents the temperature range corresponding to the melting point of the drug. No such peak was observed in the case of IMT-SLN, rather a small endothermic peak was observed close to $55-60^{\circ} \mathrm{C}$, which could be associated with that of the solid lipid. The disappearance of the endothermic peak associated with free drug in the case of IMT-SLN supported the assumption that the drug was well encapsulated within the carrier system either in molecularly dispersed state or in amorphous state $(13,33)$. XRD pattern of IMT-SLN, along with XRD patterns of free IMT and PcA, is shown in Fig. 5b. As can be clearly observed in Fig. 5b, characteristic peaks associated with IMT appeared at 17.2, 18.1, 19.7, 21.1, 24.2 , and 25.3, which were in agreement with data from a previous report (2). These characteristic peaks did not appear in the case of IMT-SLN, which provided additional support to the assumption that the drug was well encapsulated within the carrier system either in molecularly dispersed state or in amorphous state (33).

\section{Physical Stability Study}

To observe the physical stability profile of the system, physical stability study on the IMT-SLN system was conducted over a period of 60 days upon storage at temperatures of 4 and $22^{\circ} \mathrm{C}$.

Tabulation of the variations in $S_{\mathrm{z}}$, PDI, and EE over the period of storage is shown in Table VIII. As shown in the table, while the system showed minimal changes in terms of $S_{\mathrm{z}}$, PDI, or EE, and thereby, exceptional stability upon storage at $4^{\circ} \mathrm{C}$, it showed marginal changes in $S_{\mathrm{z}}$, PDI, and EE upon storage at $22^{\circ} \mathrm{C}$. This behavior of the system was expected, as upon storage, lipid nanoparticles generally show an increase in size and decrease in encapsulation $(33,34)$. Nevertheless, the system remained well within the acceptable ranges of all parameters at $22^{\circ} \mathrm{C}$, showing good stability upon storage at room temperature as well. However, because the storage stability

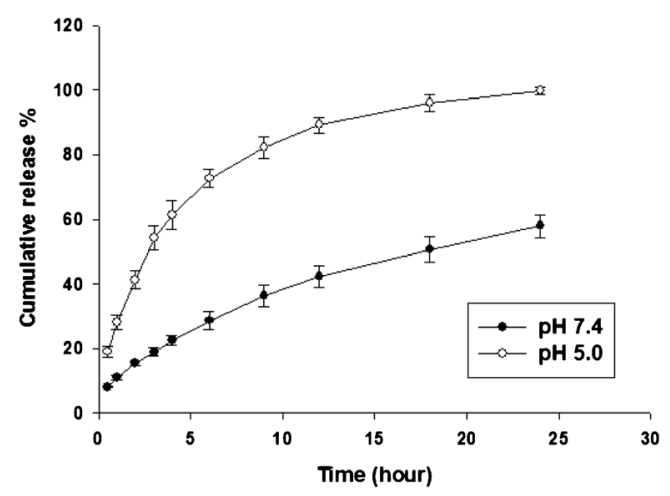

Fig. 6. In vitro drug release profile of the IMT-SLN system 
Table IX. Correlation Coefficients and Rate Constants for Fitted In Vitro Release Models

\begin{tabular}{|c|c|c|c|c|c|c|}
\hline \multirow[t]{2}{*}{ Models } & \multicolumn{3}{|c|}{ pH 7.4} & \multicolumn{3}{|c|}{ pH 5.0} \\
\hline & $K$ & $r^{2}$ & $n$ & $K$ & $r^{2}$ & $n$ \\
\hline Zero order & 2.1131 & 0.9508 & - & 4.2062 & 0.8199 & - \\
\hline First order & 0.0746 & 0.7931 & - & 0.0770 & 0.6581 & - \\
\hline Higuchi & 11.4985 & 0.9934 & - & 27.8201 & 0.8929 & - \\
\hline Korsmeyer-Peppas & 11.0684 & 0.9979 & 0.5254 & 29.1222 & 0.9729 & 0.4652 \\
\hline
\end{tabular}

$K$ rate constant, $r^{2}$ correlation coefficient, $n$ release exponent

was considerably better at $4^{\circ} \mathrm{C}$, storage of IMT-SLN in a refrigerator at $4^{\circ} \mathrm{C}$ was recommended.

\section{In Vitro Release Study}

The in vitro release profiles of IMT from IMT-SLN at $\mathrm{pH}$ 7.4 and $\mathrm{pH} 5.0$ are shown in Fig. 6. The cumulative drug release was expressed as percentage of total drug and demonstrated as a function of time. IMT-SLN showed a sustained drug release pattern at both $\mathrm{pH} 7.4$ and $\mathrm{pH}$ 5.0. However, the rate of IMT release from IMT-SLN was markedly higher at $\mathrm{pH}$ 5.0, compared to $\mathrm{pH}$ 7.4. Tumor tissues have been reported to show $\mathrm{pH}$ levels in the acidic ranges, and the accelerated rate of drug release at lower $\mathrm{pH}$ indicates that IMT-SLN remains relatively stable in circulation while undergoing physicochemical changes inside tumor tissues to permit localized drug release inside the tumor environment $(35,36)$.

The in vitro release data at $\mathrm{pH} 7.4$ and $\mathrm{pH} 5.0$ were fitted to four mathematical models: zero-order, first-order, Higuchi, and Korsmeyer-Peppas models using KinetDS 3.0 software. The respective rate constant $(K)$ and correlation coefficient $\left(r^{2}\right)$ values, along with the release exponent $(n)$ values for the Korsmeyer-Peppas model, are shown in Table IX. Mathematical modeling of the in vitro release data demonstrated that IMT release from IMT-SLN followed the Korsmeyer-Peppas model, as indicated by the maximum corresponding $r^{2}$ values of 0.9979 and 0.9729 for release at $\mathrm{pH} 7.4$ and $\mathrm{pH} 5.0$, respectively. The release exponent $(n)$ values of 0.5254 and 0.4652 (greater than 0.45 ) indicate that the drug release mechanism followed anomalous or non-Fickian diffusion, involving drug diffusion from the lipid core as well as erosion of the lipid core $(37,38)$.

\section{CONCLUSIONS}

In the current study, a combination of two experimental design approaches was used for optimization and preparation of IMT-SLN: PBD for initial screening for identification of the most significant variables and $\mathrm{BBD}$ for optimization of the variables found to be significant by PBD. Use of the aforementioned experimental design approach enabled a clear understanding of the effects of various formulation variables on IMT-SLN characteristics and accurate prediction of the relationships between them and was thereby helpful in successfully optimizing the formulation variables for preparation of IMT-SLN showing excellent physicochemical and in vitro drug release characteristics.

\section{ACKNOWLEDGMENTS}

This research was supported by the National Research Foundation of Korea (NRF) grant funded by the Korea government (MSIP) (No. 2015R1A2A2A01004118, 2015R1A2A2A04004806). This work was also supported by the Medical Research Center Program (2015R1A5A2009124) through the NRF funded by MSIP.

\section{REFERENCES}

1. Deininger M, Buchdunger E, Druker BJ. The development of imatinib as a therapeutic agent for chronic myeloid leukemia. Blood. 2005;105:2640-53.

2. Al-Hadiya BMH, Bakheit AHH, Abd-Elgalil AA. Imatinib mesylate. In: Brittain HG, editor. Profiles of drug substances, excipients, and related methodology. San Diego: Elsevier Inc.; 2014. p. 265-97.

3. Harde H, Das M, Jain S. Solid lipid nanoparticles: an oral bioavailability enhancer vehicle. Expert Opin Drug Deliv. 2011;8:1407-24.

4. Gündüz H, Özlü Y, Yalçin S. Process for the preparation of imatinib base. US Patent No. US8252926 B2. 2012.

5. Müller RH, Mäder K, Gohla S. Solid lipid nanoparticles for controlled drug delivery - a review of the state of the art. Eur J Pharm Biopharm. 2000;50:161-77.

6. Mehnert W, Mäder K. Solid lipid nanoparticles: production, characterization and applications. Adv Drug Deliv Rev. 2001;47:165-96.

7. Wissing SA, Kayser O, Müller RH. Solid lipid nanoparticles for parenteral drug delivery. Adv Drug Deliv Rev. 2004;56:1257-72.

8. Üner M, Yener G. Importance of solid lipid nanoparticles (SLN) in various administration routes and future perspectives. Int $\mathbf{J}$ Nanomedicine. 2007;2:289-300.

9. Li H, Zhao X, Ma Y, Zhai G, Li L, Lou H. Enhancement of gastrointestinal absorption of quercetin by solid lipid nanoparticles. J Control Release. 2009;133:238-44.

10. Fonte P, Nogueira T, Gehm C, Ferreira D, Sarmento B. Chitosancoated solid lipid nanoparticles enhance oral absorption of insulin. Drug Deliv Transl Res. 2011;1:299-308.

11. Lobovkina T, Jacobson GB, Gonzalez-Gonzalez E, Hickerson $\mathrm{RP}$, Leake D, Kaspar RL, et al. In vivo sustained release of siRNA from solid lipid nanoparticles. ACS Nano. 2011;5:9977-83.

12. Montenegro L, Sinico C, Castangia I, Carbone C, Puglisi G. Idebenone-loaded solid lipid nanoparticles for drug delivery to the skin: in vitro evaluation. Int J Pharm. 2012;434:169-74.

13. Shi S, Han L, Deng L, Zhang Y, Shen H, Gong T, et al. Dual drug (microRNA-34a and paclitaxel)-loaded functional solid lipid nanoparticles for synergistic cancer cell suppression. J Control Release. 2014;194:228-37.

14. Pople PV, Singh KK. Development and evaluation of topical formulation containing solid lipid nanoparticles of vitamin A. AAPS PharmSciTech. 2006;7(4):E63-9.

15. Lionberger RA, Lee SL, Lee L, Raw A, Yu LX. Quality by design: concepts for ANDAs. AAPS J. 2008;10:268-76. 
16. Poudel BK, Marasini N, Tran TH, Choi HG, Yong CS, Kim JO. Formulation, characterization and optimization of valsartan selfmicroemulsifying drug delivery system using statistical design of experiments. Chem Pharm Bull. 2012;60:1409-18.

17. Dejaegher B, Heyden YV. Experimental designs and their recent advances in set-up, data interpretation, and analytical applications. J Pharm Biomed Anal. 2011;56:141-58.

18. Gupta B, Poudel BK, Tran TH, Pradhan R, Cho HJ, Jeong JH, et al. Modulation of pharmacokinetic and cytotoxicity profile of imatinib base by employing optimized nanostructured lipid carriers. Pharm Res. 2015. doi:10.1007/s11095-015-1673-7.

19. Velpandian T, Mathur R, Agarwal NK, Arora B, Kumar L, Gupta SK. Development and validation of a simple liquid chromatographic method with ultraviolet detection for the determination of imatinib in biological samples. J Chromatogr B. 2004;804:431-4.

20. Ramasamy T, Khandasami US, Ruttala H, Shanmugam S. Development of solid lipid nanoparticles enriched hydrogels for topical delivery of anti-fungal agent. Macomol Res. 2012;20:682-92.

21. Wang S, Chen T, Chen R, Hu Y, Chen M, Wang Y. Emodin loaded solid lipid nanoparticles: preparation, characterization and antitumor activity studies. Int J Pharm. 2012;430:238-46.

22. Yuan Q, Han J, Cong W, Ge Y, Ma D, Dai Z, et al. Docetaxelloaded solid lipid nanoparticles suppress breast cancer cells growth with reduced myelosuppression toxicity. Int J Nanomedicine. 2014;9:4829-46.

23. Das S, Chaudhury A. Recent advances in lipid nanoparticle formulations with solid matrix for oral drug delivery. AAPS PharmSciTech. 2011;12(1):62-76.

24. Derringer G, Suich R. Simultaneous optimization of several response variables. J Qual Technol. 1980;2:214-9.

25. Selvamuthukumar S, Velmurugan R. Nanostructured lipid carriers: a potential drug carrier for cancer chemotherapy. Lipids Health Dis. 2012;11:159-66.

26. Lainé AL, Gravier J, Henry M, Sancey L, Béjaud J, Pancani E, et al. Conventional versus stealth lipid nanoparticles: formulation and in vivo fate prediction through FRET monitoring. J Control Release. 2014;188:1-8.

27. Moghimi SM, Hunter AC, Murray JC. Long-circulating and target-specific nanoparticles: theory to practice. Pharmacol Rev. 2001;53:283-318.
28. Zhang C, Gu C, Peng F, Liu W, Wan J, Xu H, et al. Preparation and optimization of triptolide-loaded solid lipid nanoparticles for oral delivery with reduced gastric irritation. Molecules. 2013;18:13340-56.

29. Hao J, Fang X, Zhou Y, Wang J, Guo F, Li F, et al. Development and optimization of solid lipid nanoparticle formulation for ophthalmic delivery of chloramphenicol using a Box-Behnken design. Int J Nanomedicine. 2011;6:683-92.

30. Shah MK, Madan P, Lin S. Preparation, in vitro evaluation and statistical optimization of carvedilol-loaded solid lipid nanoparticles for lymphatic absorption via oral administration. Pharm Dev Technol. 2014;19:475-85.

31. Zhang X, Liu J, Qiao H, Liu H, Ni J, Zhang W, et al. Formulation optimization of dihydroartemisinin nanostructured lipid carrier using response surface methodology. Powder Technol. 2010;197:120-8.

32. Sofou S. Radionuclide carriers for targeting of cancer. Int $\mathbf{J}$ Nanomedicine. 2008;3:181-99.

33. Tran TH, Ramasamy T, Truong DH, Shin BS, Choi HG, Yong CS, et al. Development of vorinostat-loaded solid lipid nanoparticles to enhance pharmacokinetics and efficacy against multidrug-resistant cancer cells. Pharm Res. 2014;31:197888.

34. Zhang XY, Qiao H, Ni JM, Shi YB, Qiang Y. Preparation of isoliquiritigenin-loaded nanostructured lipid carrier and the in vivo evaluation in tumor-bearing mice. Eur J Pharm Sci. 2013;49:411-22.

35. Shen Y, Tang H, Radosz M, Van Kirk E, Murdoch WJ. pHresponsive nanoparticles for cancer drug delivery. In: Jain KK, editor. Drug delivery systems (methods in molecular biology). New Jersey: Humana Press; 2008. p. 183-216.

36. Gao W, Chan J, Farokhzad OC. pH-responsive nanoparticles for drug delivery. Mol Pharm. 2010;7:1913-20.

37. Pradhan R, Kim Y, Chang SW, Kim JO. Preparation and evaluation of once-daily sustained-release coated tablets of tolterodine-L-tartrate. Int J Pharm. 2014;460:205-11.

38. Arora G, Malik K, Singh I, Arora S, Rana V. Formulation and evaluation of controlled release matrix mucoadhesive tablets of domperidone using Salvia plebeian gum. J Adv Pharm Technol Res. 2011;2:163-9. 